\title{
Aportes PaRa la Historia DE la UNIVERSIDAD NAGIONAL DË SAN Antonio Abad del GuZGo*
}

\author{
José Tamayo Herrera \\ Miembro de Número de la Academia Nacional de la Historia \\ "Con la verdad no ofendo ni temo. \\ Con caridad para todos, sin maledicencia para nadie" \\ Abraham Lincoln
}

I

Las grandes instituciones y su historia son como las altas montañas, nadie las ignora, todos las perciben desde la profundidad de los valles, pero pocos se empinaron hasta su cima para nutrirse de sus paradigmas. San Antonio Abad y su dramática historia caben en esta metáfora de manera perfecta. Pues si bien todos somos conscientes, sobre todo ustedes, distinguidos profesores y alumnos, de su añeja pátina de trescientos años, necesitamos sin embargo revisitar y recordar su historia, día a día, para nutrirnos de su tradición andina y encontrar en ambas los modelos que nos permitan enfrentar los desafios del presente y del futuro, sobre todo ahora en que las universidades improvisadas brotan como hongos en todos los extremos del Perú.

La historia ha sido siempre maestra de la vida, como dijera el viejo Cicerón, debemos acudir a ella, no sólo para informarnos de los acontecimientos del pasado, a la manera tradicional, sino sobre todo para penetrar en su mentalidad y explicarnos así lo peculiar de sus procesos y descubrir la maniera, el estilo propio, con que se forjaron y funcionaron y cómo aquella nos afecta todavía en el momento presente, utilizando la historia moderna de annales. No en vano la gran lucha social del Perú de hoy es la de la conquista definitiva de la modernidad e igualdad.

Acudimos por eso a la Historia de San Antonio Abad, a sus respetables tres largos siglos de diacronía, para con respeto reverente contemplar cimas y simas, aciertos y errores, gloria y frustraciones, justicias e injusticias. La Historia de San Antonio Abad, como esos ríos cimbreantes de la Amazonía está llena de meandros y cataratas, de rápidos y remansos, de glorias auténticas y períodos de obscuridad y deterioro. Como los cuadros de Rembrandt o de Vermeer, tiene la magia de sus claroscuros, la impronta de sus esfuminos, el delineado de lo más valioso y doloroso de nuestra Historia Regional: la pujante energía del pueblo incaico y la sinceridad de su mente, comparada con la mentalidad sinuosa del español que trajo al Perú la codicia por el oro, la ambición personal, la emulación excesiva, trayendo a nuestro propio psiquismo los vicios que a veces afloran en nuestro subconsciente.

Hoy que en el desconcertado y confuso Perú -país de desconcertadas gentes, como decía Piérola- el Estado desbordado y la sociedad nacional emergente que han surgido en esta primera década del siglo XXI, como afirma José Matos Mar, en un apasionante libro que acaba de salir, han arrasado con bastante de la mística y la originalidad de sus instituciones tradicionales y es por eso conveniente, importante y pedagógico, reflexionar sobre la importancia de la Historia de una institución, como sustento firme y núcleo duro de la esencia y la imagen de las más importantes y auténticas instituciones regionales.

Esto se hace más necesario porque en medio de tantas instituciones universitarias novísimas, de decenas de universidades que como niños recién nacidos, todavía no han aprendido a gatear por sí mismas, que están buscando caminos en pos de

* Discurso de Orden con motivo de la concesión al autor del Grado de Doctor Honoris Causa, el 27 de abril de 2012. 
estabilizarse y adquirir madurez; una universidad con 320 años es realmente algo tan excepcional en el Perú de hoy que parece increíble. Este alud o lloqlla de algunas universidades privadas (no todas) responde al impulso de que en nuestro país una de las actividades más fáciles y lucrativas es vender o negociar diplomas por sumas importantes sin pagar ningún impuesto. Algunas de las universidades" privadas son puro negocio, pues solo buscan cobrar mucho a sus alumnos, pagar mal a sus profesores y empapelar con títulos de poco valor la frente de sus egresados, sin ofrecer conocimientos modernamente válidos. Maldito el esplendor de la apariencia, como decía Goethe. Otro caso es el escapismo de algunas universidades privadas contemporáneas, en que no les preocupan los problemas nacionales, ni regionales. Ya quedó en el pasado, la idea que la universidad era una República de maestros y alumnos, con espiritu de claustro y ahora sólo es un negocio con sabor a mercado, por lo menos en Lima y por eso, porque sólo las mueve el afán de lucro. Algunas universidades privadas han creado, con sus sucursales, filiales y agencias en general, diseminadas por todo el territorio del Perú, por Costa, Sierra y Selva y por eso mismo están mal vistas y el Estado es demasiado débil para poner orden, porque la Asamblea de Rectores no puede imponer disciplina, ni planificar un desarrollo universitario racional ni acreditar a sus miembros de todo el Perú, porque teniendo 30 millones de habitantes, tenemos más de 100 universidades, la mayoría privadas y así duplicamos el número de universidades de Francia, que tiene el doble de nuestra población y sólo la mitad de verdaderas universidades. Una universidad limeña ha llegado a tener una filial en el paupérrimo distrito de Maras, provincia de Urubamba, sin que sepamos con qué recursos humanos, técnicos e infraestructurales cuenta.

Hoy los clásicos principios de la Reforma Universitaria de Córdoba por las que luchamos las generaciones anteriores y conocíamos de memoria con reverencia en mi época, sobre todo la autonomía y la Libertad de Cátedra, y el cogobierno casi están por desaparecer. En mi época solo habían cinco universidades nacionales en el Perú y una sola privada en Lima: la PUCP. La Universidad privada parece ser eficiente en algunos casos para producir graduados para el mercado y para la empresa regional o nacional, caso de la Universidad Andina del Cuzco, pero las otras universidades privadas, resultan muy caras para las clases medias y por eso se han vuelto elitistas y sus graduados carecen de sensibilidad social en su mayoría, aunque hay excepciones, como en todo.

Fujimori dio el puntillazo a la universidad nacional tradicional, como República de maestros $y$ alumnos, como institución que tenía espiritu de claustro, al convertir las universidades en sociedades anónimas y anuló parte de la investigación existente, cuando fomentó el bachillerato automático. Fujimori, como un tigre todavía no saciado con estas medidas privatizadoras anti académicas, mandó al tacho de la basura una tradición de siglos en el Perú, al disponer que las universidades podían adquirir la estructura de un negocio o de una sociedad anónima y que podían venderse como si la ciencia fuera una mercancía, una torta o un semoviente. Como respuesta a esta política equivocada surgieron como hongos las universidades privadas en Lima y el interior, fundando filiales a todo lo ancho y lo largo del Perú, a veces, con profesores improvisados y mal pagados. Se multiplicaron como un sida, sin control médico, al punto que en el Cuzco, me dicen que hay 10 o 12 filiales de universidades, manejadas desde Lima, desde Trujillo o desde Perico de los Palotes. Lo que importa al final no es el nivel científico logrado, sino el cartón, aunque este no garantice ni conocimiento, ni ocupación. Como decía el doctor Estuardo Núñez Hague, esta es una vergonzosa simulación de la ciencia y como afirmaba don Luis Valcárcel, el título sólo borra las minusvalías de la persona y favorece su afán de emergencia, sin acreditar ciertamente algún valor científico. Es decir, es una simple carcatura coartada o justificación para presentar a sus padres cualquier título o cartón adquirido como sea y mucho de nuestros títulos universitarios, algunos de los cuales se otorgan por correo oficial o electrónico, llamando a esto educación a distancia y que sólo son el substituto de los títulos coloniales, como los que se adquirieron ilícitamente por los mineros y encomenderos españoles enriquecidos del siglo XVIII que compraban Títulos de Castilla al Rey de España, en elevadas sumas, simulando una supuesta limpieza de sangre.

\section{II}

En medio de tantas instituciones improvisadas que hemos descrito con valentía y que no tienen historia alguna, San Antonio Abad posee una tradición centenaria forjada en una 
larga lucha por su superación y su creatividad que son bienes tan preciados, un paradigma tan inspirador, indispensable resaltar su importancia, precisamente ahora en que San Antonio Abad, como un viejo acorazado de 300 años, vive rodeado de un cardumen de bolicheras académicas, que pretenden inútilmente hacerle sombra. San Antonio Abad es la universidad más antigua del Perí Profundo. La única que ha tenido vida continua a lo largo de tres siglos en el Ande y en la Sierra y como decía Higuet a propósito de la tradición en la universidad inglesa: los teóricos de la educación superior que trabajan con métodos científicos, rara vez la mencionan porque parece irracional, no puede ser coordinada en planes elaborados en las Oficinas de Planificación o controlada por el Consejo Universitario. Puede ser estudiada por análisis, aunque quizás resulte dañada en el proceso y sin duda no explicada por completo. Existen mejores condiciones cuando se habla poco de ella. Algunos que perciben su fuerza con mayor ímpetu, nunca la mencionan. Algunos la vituperan, otras la ignoran o menosprecian, pero está siempre presente e invicta; esa fuerza oculta, esa energía escondida que es la tradición de una Universidad, Facultad o Colegio antiguo y dueño de una prestancia que sólo da la pátina del tiempo. Una vieja universidad donde grandes hombres fueron adolescentes y alumnos devotos alguna vez. Una universidad de varios siglos de antigüedad, con su biblioteca llena de libros añejos. Esa es la tradición de una universidad vieja que trasunta una energía y una vida espiritual independiente y sorprendente, un aura o efluvio que lo rodea todo sin que apenas lo sintamos, como sucede en Harvard, Cambridge u Oxford. Algo que es mucho más que los edificios, los maestros y los alumnos de cada una de las épocas de su historia $y$ que se manifiesta como una fuerza estimulante y poderosa, sobre la formación de las mentes de sus alumnos, sobre todo sobre el carácter, la vocación y la honradez y honorabilidad de sus graduados e investigadores. Eso es lo que la tradición conserva, pero que al mismo tiempo cambia, que se recicla y retroalimenta con nuevas ideas y proyecta modelos nuevos, que se renuevan como las hojas y las flores después del invierno, con la caricia del sol del estudio. Es una forma de energía social que inspira una mística, que mueve a los hombres, porque como decía Marx: lo antiguo pucde ser también lo nuevo y como afirmaba Mariátegui: la más añeja tradición ha sido reencontrada por los espíritus más renovadores.

\section{III}

Hay otro elemento fundamental en la historia y en la tradición de San Antonio Abad, su entorno y el medio circundante, la circunstancia orteguiana en el cual nuestra universidad está enclavada. Mientras que otras instituciones universitarias del Perú y Sudamérica han surgido en regiones de pobre solera histórica, San Antonio Abad es el reflejo de la energía social de la cultura extraordinaria del Cuzco: la ciudad más antigua del Continente Americano, la abuela del Hemisferio Occidental y la Capital Histórica del Perú, una antigua urbe creadora que ha emanado cultura y poder desde hace 3,500 años, un foco creador de larga duración, en el sentido de Braudel, una fuente permanente de incanidad, vida comunitaria y reciprocidad andina. Una ciudad con un gran pasado y sobre todo con un gran futuro. Si sabemos que la cultura es un feed back, una interacción entre el grupo social y el medio circundante, como lo observaron Taine, Toynbee y Braudel, en el siglo XX. La cultura y el estilo académico del Cuzco incásico se reflejan sin duda en la cultura superior del Cuzco y en su universidad donde dominan la peruanología, la mentalidad andino-sincrética, el estilo social montañés, la idiosincrasia y mentalidad serrana, la reciprocidad andina y la tecnología universal unidos en el amor a la tierra reflejado en el Culto a la Pachamama, aún viviente, según nuestras creencias más intimas. Todas estas categorías cuzqueñas se han reflejado en San Antonio Abad subliminalmente, como dos vasos comunicantes; y han entremezclado su creatividad de tal manera en 300 años, en la larga duración braudeliana, que no sabríamos si San Antonio Abad es el efluvio de la cultura andina del Cuzco incásico o del Cuzco actual, La Capital Histórica del Perú, la sociedad soñada por los amautas, los penates y chamanes de la Cultura Inca, desde sus fortalezas ideológicas encerradas entre las breñas de los Andes y los tsunamis de sus ríos, como bastiones y regiones de refugio frente a lo Occidental. Por eso quizás en cierto modo, soñando un poco, pudiéramos decir que San Antonio Abad, pese a los siglos transcurridos y al cambio de tiempos, de cultura y de época, es todavía un poco la continuadora de la misteriosa Universidad de la ldolatría, donde mora la religión andina clandestina que tantos cronistas y arqueólogos, antropólogos y aventureros han imaginado, buscado y admirado y continúan explorando y buscando a sus sacerdotes misteriosos. ¿Cómo explicar entonces el milagro sincrético de 
Qoillur Riti? El Cuzco de 35 siglos y nuestra Alma Mater de tres siglos son como las dos caras de una misma moneda, la identidad regional cuzqueña, nuestro subterráneo y al mismo tiempo invicto, siempre renovado incaísmo, como yo lo llamo e incanismo, como lo llama Jorge Flores Ochoa, el gran antropólogo cuzqueño.

Y así como de la tierra del cercano Valle Sagrado de los Incas brota como una erupción de dulzor y blancura el mejor maíz del mundo, producido por la tierra gloriosa del Valle del Urubamba. La Pachamama, lo que hoy se llama el Medio Ambiente o Medio Ecológico, determina el alma de la población enclavada en el área de del Cuzco proviene de una etnia indo-hispana en que lo inka y lo americano original lleva gran parte de su peculiaridad y de su idiosincrasia.

\section{IV}

El origen más remoto de San Antonio Abad podemos rastrearlo desde la fundación del Seminario de su mismo nombre por el obispo Antonio de La Raya, el 1 de agosto de 1598. Poco después surge en el Cuzco el primer anhelo por una universidad propia. Los notables, encabezados por Pedro del Pesso de Vera, realizan una probanza ante las autoridades coloniales, pidiendo la erección de una universidad en el Cuzco. El Obispo de La Raya justificó su petición, basándose en el hecho de que Lima y Cuzco tenían climas diferentes. Lima tenía un clima malsano (y aún lo tiene), para los serranos; seguramente aludía a la malaria que era una plaga terrible en los valles de la Costa. En cambio, el Cuzco era abundante en comida y vivienda barata, con un clima saludable y frío lo que suponía condiciones favorables para ser una Ciudad Universitaria. El anhelo cuzqueño del siglo XVII por tener una universidad propia fue aprovechado por los comandos del Papado: los Jesuitas, quienes el 9 de julio de 1621 lograron la expedición de la bula In Supereminente Sedes Specula, expedida por el Papa Gregorio XV, por medio de la cual se fundó la Universidad Jesuítica de San Ignacio de Loyola.

\section{V}

Fundados la Universidad Jesuítica y el Real Colegio de San Bernardo, empezaron las rivalidades de los estudiantes de estas dos instituciones, con los alumnos del Seminario de San Antonio Abad. Los primeros, los de San Bernardo, eran ricos y forasteros, los segundos, los de San Antonio Abad, pobres y nativos. Los alumnos de los Jesuitas usaban la beca azul y los de San Antonio la beca roja, el color de la renovación.

Injustamente, la Universidad Jesuítica de San Ignacio negaba los grados a los antonianos, esto estimuló el deseo de estos últimos de contar con una Universidad propia. Fueron los frailes dominicos los gestores de la fundación de la Universidad San Antonio Abad, principalmente el Padre Leoncio López Dávalos, quien viajó a Madrid y Roma para hacer los trámites necesarios y fortalecer su petición, e imprimió en Madrid y Roma, dos libros del Lunarejo, Don fuan de Espinoza y Medrano, la máxima lumbrera del Seminario 
de San Antonio Abad, cuyos libros La Novena Maravilla, (hoy reeditada) y la Lógica que trata sobre el Problema de los Universales, fue traducida y publicada por Walter Redmond hace más de 30 años.

Por fin después de muchas gestiones, el 1 de marzo de 1692, del cual pasan más de 300 años, el Papa Inocencio XII expidió el breve de erección denominado Aeterna Sapientiae, el cual fue confirmado por Real Cédula del 1 de junio de 1692. Había nacido como Real Pontificia, la Universidad Nacional San Antonio Abad del Cuzco, hace ya más de 300 años. Pero los obstáculos y el vía crucis para su efectivo funcionamiento fueron innumerables y no había terminado todavía el ascenso a la cumbre de la montaña de los antonianos.

Pues inmediatamente, los jesuitas de San Ignacio, promovieron un pleito y se opusieron al funcionamiento de San Antonio Abad, denigrando la enseñanza que se daba en el Seminario, fundado por el Obispo de La Raya. Alegaban que era absurdo que en el Cuzco funcionaran simultáneamente dos universidades, porque eso crearía rivalidades con vilipendios mutuos y constantes desordenes. Se inició un largo pleito que tuvo que ser resuelto por la Audiencia. El Obispo Mollinedo y Angulo pretendió, en una forma muy sutil, favorecer a los Jesuitas. Entonces los alumnos del Seminario de San Antonio Abad se declararon en huelga -la primera huelga de los alumnos de nuestra universidad-y fue el comienzo de una tradición y un modo de lucha que nunca dejarían los antonianos y el Colegio quedó desierto. Mollinedo ante estos hechos cambió su conducta y por fin la Audiencia expidió la sentencia el 9 de julio de 1696, por la cual fallaba a favor de San Antonio Abad, burlando a los inteligentes Jesuitas, los mismos que contumaces en su oposición, apelaron el pleito y el asunto hasta el Consejo de Indias, en Madrid, pero al fin fracasaron en sus intentos jurídicos. El Consejo de Indias confirmó en 1699 todo lo obrado por la Audiencia de Lima, a favor de San Antonio Abad. Por fin después de un largo vía crucis de 91 años, la Universidad de San Antonio Abad empezó a funcionar, siendo su primer Rector Don Juan de Cárdenas y Céspedes y su primer graduado, don Pedro de Oyardo quien optó al Grado de Doctor en Teología el 5 de noviembre de 1696.

Así el Cuzco, a diferencia de Lima que era la Ciudad mimada de los Virreyes y la Reyna de Sudamérica, la Ciudad Imperial, tenía dos universidades durante el Siglo XVIII, caso único en el Perú y Sudamérica. Se convirtió en una ciudad universitaria auténtica, con sus dos grandes universidades, San Anto Abad y San Ignacio. La Primera seguía la doctrina tomista de los Dominicos, la segunda el suarismo jesuita del Renacimiento. Las rivalidades entre los alumnos de ambas universidades, produjeron numerosas grescas y desordenes, peleas callejeras y escándalos frecuentes, como los que ocurrieron en el entierro de Mollinedo y Angulo en 1699.

San Antonio Abad tenía entre 80 y 120 alumnos y San Bernardo que alimentaba a San Ignacio, apenas 60. Los de San Antonio Abad eran mayoritariamente mestizos y pobres y los ignacianos, blancos y ricos. Una profunda rivalidad de etnia y de clase y en cierta forma de estamentos, alimentaba las diferencias entre los alumnos de ambas universidades cuzqueñas.

\section{VI}

La Universidad Colonial, en este caso San Antonio Abad, en el Cuzco, representaba la Escolástica, era tomista, uncida al silogismo y al comentario de Aristóteles, a través de la misión tomista medieval del pensamiento del Estagirita, contenido en la Summa Teológica de Santo Tomás de Aquino.

Su pensamiento todavía reflejaba la influencia del Sentenciario de Pedro Lombardo, el lógico y teólogo del siglo XII y los antonianos juraban no apartarse de la corriente tomista, porque entonces como ahora los católicos estaban divididos por concepciones teológico-sociales, como ocurre ahora en el 2012.

La Ciencia Natural, la fisico-matemática, surgida del pensamiento de Descartes y cultivada por los científicos naturalistas rebeldes a la Iglesia oficial, tan poderosa en la Edad Moderna, no asomaba por ninguna parte en los estudios de los universitarios antonianos. El gran personaje antoniano de esta época fue El Lunarejo, don fuan Espinoza y Medrano, polígrafo extraordinario que asombró a sus auditorios con sus discursos plenos de una retórica conceptista y culterana y que incursionó además en la Filosofia y la Lógica, tomando un posición original y radical frente al intrincado problema de los universales, típicamente medieval, y que frente a todo esto se dio tiempo para escribir el Apologético en favor de don Luis de Góngora y Argote, magnífica pieza literaria 
del culteranismo en lenguaje español. No está demás indicar que el Lunargjo dominaba el latín, conocía bien el griego, jugaba con el español, con el desparpajo de un niño y conocía algo del idioma israelita y todo esto logrado gracias al estudio de los grandes maestros antonianos y de la autoformación y el autodidactismo. Es sin duda la estrella fulgurante e inigualada del Seminario y la.Universidad de San Antonio Abad. Junto a él, nosotros descubrimos el nombre y el retrato, que se halla en el Convento Franciscano de Quito-Ecuador, de Don Pedro de Alva y Astorga, sacerdote franciscano graduado en San Antonio Abad y el único antoniano que ha ceñido el capelo de Cardenal de la Iglesia Católica Romana y que es autor prolífico de libros teológicos, escritos en latín que se hallan en la Biblioteca Jesuítica que todavía posee San Antonio Abad hasta hoy. Junto a ellos, también destaca Vasco de Valverde y Contreras que fue Rector de San Marcos, por encima de los graduados de la universidad limeña.

\section{VII}

Los concursos y oposiciones para cubrir las cátedras del siglo XVIII eran originalísimos y divertidos; el postulante -sorteado el punto a tratarse al día siguiente- tenía sólo 24 horas de plazo para prepararse para su sustentación. Esa noche de preparación por el tiempo angustioso que disponía, se denominaba La noche triste, pues el postulante debía pasarla en vela estudiando y preparándose para el combate dialéctico con sus Jurados al día siguiente.

En el libro de oposiciones a las cátedras de San Antonio Abad, consta a fojas 92 vuelta, que el postulante Don Juan de Dios Calvo y Antequera sorteó sus puntos el 26 de setiembre de 1758, habiéndole tocado un tema de la Física de Aristóteles. Tres horas después comunicó al Rector y al Jurado que le habían acometido temblores y que desistía a la oposición a cátedra. Seguramente por su miedo terrible a entrar en la noche triste con sus menguados conocimientos sobre el Estagirita.

\section{VIII}

Expulsados los Jesuitas injustamente por el Rey, en 1767, desapareció la Universidad de San Ignacio y San Antonio Abad quedó sola, campeando en la vida intelectual del Cuzco, como su único foco de grados y de sabiduría. Los antonianos poco cristiana y cruelmente festejaron la disolución de la universidad rival. Existen también fuentes pictóricas sobre la Universidad Colonial, pues en los extraordinarios lienzos cuzqueños denominados El huerto de San Antonio Abad y El Olivo de Antonio, han quedado bajo una iconografía simbólica de contenido histórico, religioso e ideológico, los retratos de los grandes personajes intelectuales de la Universidad de San Antonio Abad que formaba el Alma Mater escolástica de la Filosofia y la Teología y las Artes del Cuzco en el siglo XVIII. Nosotros, todavía en 1970, descubrimos estos cuadros para la Ciencia y los publicamos en el número $1^{\circ}$ de la Revista Teqse, con hermosas fotos en blanco y negro, y llamamos a esta corriente pictórica como Simbolismo Historiográfico Cuzqueño y que después estudió Francisco Statsny. Como de costumbre, los limeños ahora descubren lo que genuinamente descubrimos los serranos, 40 años antes, y en el año 2011 ha salido de las prensas, una edición de la Novena Maravilla, con una foto a color del Huerto de San Antonio Abad, como un descubrimiento sensacional, silenciando lo que nosotros descubrimos hace 42 años, publicando una fotografia completa del cuadro en la revista Teqse, en blanco y negro e intentamos una investigación de los pareados con que se designaban a los frutos del árbol científico del Cuzco Colonial. E igualmente, presentamos el Olivo de Antonio, donde se muestra a José Pérez Armendáriz y a todos sus colegas y discípulos en San Antonio Abad, entre 1769 y 1805; cuadro que parece que al presente ha desaparecido, como parte de la diáspora delictual de nuestro patrimonio pictórico y archivístico, estimulada por el clímax económico de la globalización que con la devaluación del dólar a nivel mundial, vuelca el interés de los rusos enriquecidos y de los príncipes sauditas millonarios que no saben dónde invertir su plata y han encontrado en el Perú, un campo virgen para expoliar su patrimonio, comprando cuadros y documentos antiguos, siendo una de las causas del robo de nuestro patrimonio artístico y documental.

\section{IX}

Llegada al Cuzco la época de la Liberación, la Universidad de San Antonio Abad, rivalizando con el Real Convictorio de San Carlos en Lima, cumplió un papel trascendental como centro de agitación patriótica y difusión de las ideas libertarias y así como Rodríguez de Mendoza en Lima, en el Cuzco, idéntico o superior papel le cupo al Rector de San Antonio Abad y después Obispo del Cuzco, don José Pérez y Armendáriz, 
quien formó y educó a la gran generación criollomestiza que luchó por la Patria en 1805 y en 1814. Pérez y Armendáriz fue el Rector que más ha durado en el gobierno de nuestra universidad: largos 37 años. Este Rector eterno de San Antonio Abad sembró en el claustro ideas subliminales y luego abiertas a favor de liberación del Perú, hasta llegar a costear con su peculio el dictado de dos cátedras, uno de Derecho Civil y otro de Derecho de Gentes, desde las cuales penetraron en San Antonio Abad el racionalismo ilustrado y las ideas enciclopedistas en las mentes ávidas de los jóvenes estudiantes antonianos ansiosos de un cambio. Lo más importante es que Pérez inculcó en sus alumnos la superación del conformismo colonial, el desprecio por el Absolutismo Ilustrado de origen borbónico y la esperanza que traían las nuevas ideas que venian a modernizar la atmósfera paralizada y obsoleta de la Universidad Colonial. Pérez fue un auténtico conductor revolucionario y modernizador de la juventud antoniana e hizo todo esto con mucha prudencia y un sigilo admirable que no permitió su represión.

Así, San Antonio Abad se convirtió en el semillero de la Revolución Emancipadora, en la incubadora que criaría los polluelos que después se convertirían en cóndores. De sus claustros salieron Antonio Valdez, numen de José Gabriel Thupa Amaro; Manuel Ubalde, el abogado mártir y conspirador de 1805; Rafael Ramírez de Avellano, el líder del constitucionalismo en 1813. José Angulo Torres, el inmortal capitán general de los Ejércitos de la Patria, en 1814 y 1815, dirigió estas tropas y su maestro Pérez llegó a formar a toda una generación de laicos y eclesiásticos en el amor a la libertad, cuyas huellas renovadoras encontraremos en las grandes revoluciones cuzqueñas contra España, al punto que el Perú antes de esperar el Bicentenario del 2021, debería festejar en el 2014 el Bicentenario del mayor intento autónomo y peruano de darnos libertad, como lo reconocen Basadre y tantos otros historiadores que saben juzgar y apreciar el esfuerzo bélico del Perú interior. San Antonio Abad fue así la universidad patriótica y revolucionaria por excelencia, el foco ideológico de la liberación militar peruana, superando largamente a San Marcos en esta tarea heroica, pues la universidad limeña no pasó de las conspiraciones en petit comité que han sido magnificadas, pero que no significaron nunca ningún peligro para Abascal, el Virrey autoritario, estratégico y contra revolucionario por excelencia.
La prueba de que la Universidad y el claustro antonianos fueron el semillero de la revolución contra España, la tenemos en el castigo que cayó de inmediato sobre nuestra Alma Mater de parte de las autoridades españalas a mediados de 1815, pues por Real Orden del 4 de mayo de 1815, se recesó la Universidad de San Antonio Abad y se dispuso que visitadores especiales investigaran la filiación política y revolucionaria de sus componentes y una inquisición de sus bienes y bibliotecas, buscando libros prohibidos. Posteriormente, por Real Cédula, en 1816, se suprimieron las cátedras y los grados en Leyes, Cánones, y Medicina, quedando la Universidad reducida a la enseñanza de Teología y Artes. La Cátedra de Derecho Civil y de Gentes, fundada por Pérez a su costa para difundir los principios democráticos, fue por supuesto suprimida, pese a los memoriales y quejas de los vecinos del Cuzco; San Antonio Abad quedó recesada por un lapso de 10 años, hasta 1825, como castigo de los chapetones realistas que querían imponerle un castigo ejemplarizador por haber sido el semillero de las ideas en pro de la liberación.

El haber abrazado tan ardientemente la causa revolucionaria le costó muy caro a San Antonio Abad. Pagó el precio de haber sido la única Universidad Colonial en el Perú, comprometida valientemente con la causa de la Independencia y de la Patria en nuestro país. Es extraño de que quienes han estudiado la Emancipación, hayan ignorado este papel de la Universidad Antoniana y pese a que la Revolución de 1814, ha sido investigada por Eguiguren, José Uriel García, Jorge Cornejo Bouroncle, Horacio Villanueva Urteaga y Manuel Jesús Aparicio Vega, además de mí mismo, José Tamayo Herrera, que elaboré un largo documento sobre la coyuntura bélica y política de 1814 , para la Historia del Ejército del Perí, no han podido conmover a los penates de la cultura peruana y del Estado y sus órganos de que el verdadero Bicentenario, con juramento por la Patria, grito de independencia y bandera propia: azul y blanca, merece ser celebrado especialmente por ser obra exclusiva de los peruanos en el 2014 y no en el 2021 o 2024, que en gran parte fueron obra de argentinos, chilenos y gran colombianos, en gran parte fue un ejército internacional, y una independencia concedida.

\section{$\mathbf{X}$}

Liberado el Cuzco por Agustín Gamarra el 25 de diciembre de 1824 y arribado el Libertador 
Simón Bolívar a la ciudad andina en junio de 1825, renació la universidad cuzqueña. Fue el 18 de julio de 1825 cuando fue restablecida por un gesto áulico, muy propio de aquellos tiempos de caudillaje, en que consideraban a Bolívar como el autor de un verdadero milagro, fue reabierta con el nombre de Universidad de San Simón. Sólo duró tres años esta universidad bolivariana. Pero pese a eso a ella se debe la publicación del primer libro cuzqueño, denominado Elementos del Derecho Natural y de Gentes de Juan Gottlieb Heinecio que fue traducido del latín al español por don Manuel de Tejada, catedrático de las lenguas castellana y latina en la Universidad de San Simón y lleva primer libro impreso en toda la historia del Cuzco, en 1533, y que constituía una traducción jurídica que demostraba el avance de las Ciencias Sociales. En 1832, restablecida ya la Universidad de San Antonio Abad en el seno del Seminario de su nombre, se publicó el primer libro técnico, editado en el Cuzco, Los Elementos de Matemáticas puestos en Compendio del doctor Manuel Ayala, el único agrimensor que existía en el Cuzco y que era a su vez tasador público y precursor de los ingenieros cuzqueños del siglo presente.

San Antonio Abad es la única universidad que sobrevive en los Andes durante el siglo XIX. Las Universidades de Huamanga y Puno, desaparecen por consunción porque la marginación decimonónica de la Sierra, causada por la Era del Guano, también las corroe y las elimina por escasez de profesores y alumnos.

San Antonio Abad, como universidad volvió a depender del Seminario de su nombre, desde 1828 hasta 1863 , y con ella a una vida inocua y exangüe, intoxicada de clericalismo y de un trasnochado escolasticismo de parroquia. Para comprender esto hay que aclarar un punto esencial que los que han historiado la diacronía de San Antonio Abad, han omitido. Como dice César Antonio Ugarte: "La universidad del siglo XIX era totalmente diferente a la del siglo XX. El concepto de Universidad, en el siglo XIX, era muy distinto al actual. La Universidad decimonónica se concibio durante gran parte del siglo XIX, como una institución dedicada solamente a conferir grados académicos y algunos títulos profesionales". No daba enseñanza científica alguna en sus aulas, ni menos investigaba la realidad circundante, ni conocía la ciencia del día. Los estudios para conseguir los grados se hacían en otras instituciones educativas diferentes y autónomas, como el Colegio de Ciencias y el Seminario de San Antonio Abad. Hasta 1866, San

Antonio Abad es un ente público sólo de nombre, porque está totalmente dominado por el clero y no efectuaba labor docente alguna. Además, sus propios estudios teológicos y filosóficos contra lo que piensa el sentido común, habían desmejorado y decaído desde la época colonial. Inútilmente el protector Santa Cruz, trató de modernizar la Universidad San Antonio Abad, pues esta seguía regida por las anacrónicas Constituciones de 1699, increíblemente vigentes en plena República.

El retardatario rector clerical doctor Julián Ochoa y Jara, se negó siempre a elaborar un nuevo Reglamento para adecuarlo a la Ley peruana y al nuevo Estado que había nacido de la Independencia. Desde Lima se lo exigían, pero Ochoa seguía tercamente encasillado en que la Universidad era Pontificia y estaba unida al Seminario Conciliar Diocesano, porque consideraba que la Universidad era sólo un órgano accesorio de su Seminario. La intelligentsia de sotana era en la sexta década del siglo XIX una rémora total para el progreso científico del Cuzco. Las Facultades solo se reunían para graduar a alguien, de tarde en tarde. De 1853 a 1858 no se había conferido grado alguno; pese a las constantes exigencias del Estado, Ochoa se negó siempre a dotarla de un nuevo y moderno reglamento porque era un verdadero ogro de estulticia y obscurantismo.

Entonces el Estado Peruano, cansado de tanta resistencia absurda y anacrónica, el 20 de marzo de 1861, ordenó la remisión del proyecto de nuevos Estatutos y obligó a la universidad a conferir grados y ante la negativa de Ochoa, dispuso su laicización, ordenando así mismo que la universidad se estableciera en el local del Colegio de Ciencias y nombró como Rector a un laico y seglar nada clerical: el doctor Enrique Gamboa. Esta fue la hazaña de secularización y laicización de la Universidad después de casi 40 años de producida la Independencia, medida que la salvó de las garras de un clero retardatario. La Reforma Prado de 1866 ordenó el establecimiento de tres Facultades: Letras, Derecho y Ciencias, nombró a sus profesores estables, aprobó el currículum y dispuso que gozara de un local propio: el antiguo local de los Jesuitas en la Plaza de Armas, el actual Paraninfo Universitario. En 1867 se matricularon los primeros alumnos.

De 1866 a 1896, la Universidad de San Antonio Abad llevó una vida accidentada, llena de problemas institucionales y económicos y sólo 
alcanzó una vida casi normal de 1869 a 1878 . Luego, la crisis de la época de Pardo y Prado y la guerra con Chile la redujeron a la inanición. El Estado dejó de enviar la subvención. La vida universitaria como consecuencia de esta crisis sufrió una nueva parálisis, los catedráticos y empleados, estuvieron sin sueldo por casi una década, prestando servicios sólo por patriotismo, sin remuneración alguna. La universidad en 1888 tenía sólo treinta y tres alumnos. Educación sólo para una élite, universidad minúscula, institución informal y exangüe.

\section{XI}

A partir de la secularización de 1863 y del inicio de las actividades docentes de 1866, se introducen en el Cuzco nuevas ideas filosóficas que reflejan la avidez por la renovación teórica. Así entró en San Antonio Abad el pensamiento krausista, la filosofia del pensador alemán Karl Cristian Krause, discípulo de la derecha hegeliana, introducido por el profesor José Teodosio Rozas que era un explorador de la selva cuzqueña, como afirma Aparicio y un explorador también del pensamiento europeo, pues llegó al krausismo a través del filósofo belga Guillermo Thiberguien. El Krausismo era una filosofia ocultista, hermética y totalmente volcada a la Metafisica y a la Teodicea. Krause parece haber sido el filósofo oficial de la masonería de la época. Estas ideas no eran ateas como algunos han dicho, sino teosóficas y gnósticas y fueron potenciadas por krausistas españoles como Salmerón, que influyeron en el pensamiento de los líderes de la universidad hasta 1909, cerca de 30 años. No está demás decir que el krausismo fue la gran plaga filosófica en la América Latina en el siglo XIX, como lo han probado las investigaciones de Roig sobre los krausistas argentinos y las de Zea sobre México. Era la corriente filosófica de moda durante las décadas finales del siglo XIX y hasta 1909 (así como lo fue, el marxismo en el siglo XX), pero sólo estudiado a nivel de manuales y no profundizado en sus obras maestras, con una verdadera labor creadora de aplicación de su teoría a nuestra realidad, salvo el caso de Mariátegui y Flores Galindo.

Otra influencia notable será la del incaísmo, corriente local multisecular que corresponde a la mentalidad cuzqueña ancestral y que fue reverdecida por obra de Pío Benigno Mesa, primer Decano de la Facultad de Letras. Esta Filosofia influyó poderosamente en las mujeres que estaban cerca de la Universidad. Como un homenaje a las damas profesoras y alumnas que me escuchan, debo decir que una mujer causó la gran revolución académica en esta universidad informal y machista. Una precursordte las actuales profesoras cuzqueñas, doña Trinidad Enríquez Ladrón de Guevara tiene el mérito de haber sido la primera mujer admitida en la Universidad Peruana, antes que en San Marcos, aunque para ello tuvo que luchar mucho contra los prejuicios de su época, hasta que logró arrancar del Estado una Resolución Suprema, del 3 de octubre de 1874, que le permitió matricularse en la Universidad para estudiar Derecho. Sus exámenes de ingreso fueron memorables porque todos fueron tomados por un jurado en forma oral. La Enríquez contestaba con soltura y brillantez las preguntas de los catedráticos. Luego de ser aprobada, noche por noche, en cada curso, estrenaba un nuevo y elegante vestido diferente para la noche siguiente y a cada uno de sus triunfos en el ingreso, seguía un sarao en su casa. Fue también la primera mujer que se graduó en el Perú de Bachiller en Jurisprudencia y como pionera de su sexo, un grupo de damas limeñas la premiaron con una medalla de oro. Una cuzqueña abrió a la mujer peruana las puertas antes herméticamente cerradas de la universidad peruana y este fue un triunfo de San Antonio Abad, realmente extraordinario para su época: 1874.

\section{XII}

La Universidad decimonónica resucita hacia 1896, dentro de la atmósfera de la Reconstrucción Nacional que acompaña al gobierno constitucional de Piérola. Se trata todavía de la universidad con rezagos krausistas que recibe y dirige el doctor don Eliseo Araujo, quien hace funcionar la universidad, imparte enseñanzas y organiza el funcionamiento académico hasta que este se normaliza, pero dentro de un orden conservador, de círculo, de élite, casi de familia que no admite ideas nuevas ni la modernización de la institución que exige el mayor número de alumnos que ingresan a sus aulas. Es el fenómeno regional que se llama Modernización Elitista Restringida o Primera Modernización que al fin vence la ataraxia del siglo XIX y cuando nuevas ideas empiezan a sacudir a algunos maestros y a casi la totalidad de los estudiantes. El Positivismo llega tardiamente a la universidad por obra del sabio naturalista y médico Antonio Lorena. Lorena había adquirido en Lima y el extranjero 
las ideas de Comte, Spencer, Lamarck y Darwin, las cuales empezó a enseñar, junto con la teoría de la Evolución, el Darwinismo Social y el interés por la Antropología Física, tan de moda en ese entonces en Europa. Lorena funda por primera vez la primigenia Cátedra de Antropología en el Perú, antes que en San Marcos y paralelamente la Etnografia y la Etnología que comienzan en el Cuzco con las investigaciones de Fortunato L. Herrera, entre los campesinos de Chinchero y de Francisco Velasco sobre los machiguengas de la amazonia cuzqueña. Los positivistas ansiosos de expandir su ideología y su filosofia, luchan desde el diario El Sol, orientados por su Director Ảngel Vega Enríquez, que acababa de volver de París centro de la cultura del mundo de entonces, para terminar con la hegemonía de los krausistas. Precisamente el Decano de la Facultad de Ciencias Sociales, doctor Oscar Paredes Pando, ha estudiado los detalles del período de nacimiento de estas nuevas ideas, entre 1901-1907-1909 y que conduce a la revolución universitaria de este último año bajo la bandera de la transformación de la universidad y la introducción de esas nuevas ideas reformistas que cuestionan el dominio que ejerce el rector y la ausencia de participación estudiantil, frente a las vaporosas lucubraciones de los krausistas, en un libro publicado el año 2011, con un gran material de archivo de primera mano, absolutamente original. Realmente la tarea de exploración investigatoria y el esfuerzo heurístico del doctor Paredes Pando ha sido novedoso e importante, pues nos ha mostrado nuevas fuentes que cubren casi un siglo y muestra una historia que había sido olvidada, la de los estudiantes, de los cuales podemos conocer mejor aspectos nuevos del movimiento de 1909 y sus antecedentes gracias al hallazgo del expediente de interpretación paleográfica de la fundación de la Universidad del Cuzco, trabajo heurístico que había sido elaborado por el bachiller Juan Pablo Villanueva y publicado en marzo del 2006 por la Universidad Nacional de San Antonio Abad del Cuzco donde se recogen trabajos de César Antonio Ugarte de 1912; de Fortunato L. Herrera, de 1913 y la de José Luis Bustamante y Rivero en su tesis doctoral, intitulada: La Crisis Universitaria de 1918 y lo escrito por José Gabriel Cosio en 1945, denominado Somera Sinopsis de su Historia.

Parcdes Pando muestra también las ideas expuestas por Julián Santisteban Ochoa en su Discurso de Orden, El CCL, Aniversario de la Universidad San Antonio Abad del Cuzco donde expone los documentos encontrados por Santisteban en España en el Archivo de Indias, documentos que fueron publicados por la Revista del Archivo Histórico del Cuzco en 1963. Así el doctor Paredes Pando se ha unido al grupo de historiador antonianos que se ocuparon de la historia de su Alma Mater y eso merece un elogio.

Posteriormente, el doctor Horacio Villanueva Urteaga, probablemente apoyándose en algunos documentos de Santisteban Ochoa, publicó un artículo denominado, La Universidad Nacional de San Antonio Abad del Cuzco (RAH del Cuzco ${ }^{\circ} 11$ ) y luego su libro Fundación de la Universidad Nacional de San Antonio Abad, Cuzco, en 1987 y luego en 1992 reedita el texto de 1963. Igualmente ese año, 1992, Manuel Jesús Aparicio en homenaje al tricentenario de la UNSAAC, leyó un breve discurso denominado Suma y Compendio de la Real y Pontificia Universidad de San Antonio Abad del Cuzco.

Paredes Pando reconoce la validez de esos trabajos académicos, pero afirma que ninguno de ellos se ha referido al rol de los alumnos en las pasadas centurias y no han tomado en cuenta el movimiento estudiantil. Esto es cierto en alguna medida, pues nosotros modestamente nos referimos a los movimientos estudiantiles en nuestros libros Historia Social del Cuzco Republicano e Historia General del Qosqo, en los cuales nos ocupamos en forma sintética pero completa y por primera vez, del movimiento de 1909 contra Eliseo Araujo y de los movimientos estudiantiles de 1957, que culminaron un 26 de setiembre de 1957, contra la opresión anti reformista de un grupo de profesores liderados por Luis Felipe Paredes que culminó en la conquista del cogobierno, con el cual la Universidad del Cuzco resultó precursora en el Perú. Luego llegamos al año 1971 y a las famosas Jornadas de Agosto que reclamaron contra el régimen vertical castrense del Decreto Ley 17437, establecido por la dictadura militar para convertir la universidad democrática de la Reforma Universitaria, en un cuartel y en un remedo de falsa democracia en que todo dependía de la voluntad todopoderosa de la suprema autoridad del rector y la UNSAAC se vio convertida en una ridícula imitación de la Fuerza Armada y de la universidad norteamericana. Contra este estado de cosas se rebelaron vastos sectores de los estudiantes, los maestros y los trabajadores no-docentes, haciendo que cayera este gobierno que encarnaba la ley castrense y que luego acabó con la intervención del CONUP, que estableció 
el Gobierno Tripartito: de profesores, estudiantes y trabajadores no-docentes que rigió los destinos de San Antonio Abad, entre el 15 de setiembre de 1971 y el 4 de enero de 1974, en que por Resolución No 1531-74-CONUP, se estableció la COGOIRE presidida por el ingeniero agrónomo Hugo Pacheco Garmendia, volviendo el Estado por tercera vez a intervenir a la UNSAAC.

El libro del doctor Paredes Pando cubre parte del siglo XX antoniano, con bastante detalle y amplio apoyo documental muy prolijo sobre la actuación de los estudiantes, siendo un importante aporte histórico sobre la UNSAAC en el siglo XX y que proviene de los investigadores de la nueva generación de San Antonio Abad, constituyendo un aporte digno de seguir por los jóvenes colegas que hoy ejercen la docencia:joven en nuestra Alma Mater. Como consejo personal de un historiador viejo como yo, me permitiría sugerirle a Paredes Pando una hermenéutica más gadameriana un manejo más atractivo de la retórica histórica, precisamente para atraer lectores para su libro. Los historiadores no olvidemos nunca que la gran prosa peruana proviene de la historia; Riva Agüero y Porras Barrenechea y sobre todo Basadre.

\section{XIII}

Para estudiar los movimientos de la juventud universitaria durante el siglo $\mathrm{XX}$, paralelos a los trabajos de investigación de los profesores y de los graduandos, diremos que en el siglo XX la UNSAAG sufrió tres intervenciones del estado peruano, la primera en 1910, la segunda en 1948 y la tercera en 1974.

Los largos trece años del rectorado de Eliseo Araujo causaron el cansancio y el descontento de los estudiantes que se levantaron en 1909, un 7 de mayo, contra este orden ultraconservador, metafisico, hermético y nepotista ocasionado por un espíritu de argolla propio de una rama de la pseudo-oligarquía cuzqueña, que tenía como filosofia caduca al krausismo alemán y español, que era la filosofía oficial de la masonería. Por eso estalló la famosa revuelta y huelga el 7 de mayo del año 1909 que duró casi un año entero y fue animada por los positivistas del diario El Sol, dirigidos por ese gran prohombre cuzqueño, desgraciadamente olvidado, Ángel Vega Enríquez, que había bebido el positivismo y las tendencias europeas durante su estancia en París a fines del siglo XIX. Vega Enríquez uno de los más grandes del siglo $\mathrm{XX}$ ha sido totalmente olvidado y murió en la miseria en el
Hospital 2 de Mayo de Lima; su tumba nunca ha podido hallarse, pues murió en 1932.

Producida la huelga, muchos conservadores en Lima quisieron suprimir la UNSAAC y las otras universidades menores, mediant una ley del Parlamento, según la cual debería centralizarse toda la educación superior en Lima y en San Marcos y que de paso arremetía contra las Universidades de Arequipa y de Trujillo que estaban tranquilas. Esta centralización de la educación superior era un delirio limeñista de la oligarquía civilista en el poder.

Entonces el gobierno de Augusto B. Leguía, defendiendo el derecho del Cuzco y las provincias a tener una universidad, intervino la UNSAAC y manu militari, nombró como rector de San Antonio Abad al joven profesor norteamericano: Alberto A. Giesecke, el 26 de febrero de 1910, personaje que prácticamente solo, animado de sus 26 años, transformó la rebeldía justa de los muchachos cuzqueños en una acción científica importante para introducir una filosofia nueva y una ciencia de punta orientada hacia la investigación de lo local, lo regional, lo histórico y lo telúrico. $\mathrm{Al}$ estirado Araujo, lejano, hierático, aristocrático y distante, lo sustituyó un hombre joven que era de la misma edad de sus alumnos, que fraternizaba con ellos mediante el deporte del tenis y tenía un gran dominio de las relaciones humanas, una gran muñeca, como diríamos hablando en criollo. Pero que no era un simple jovencito de origen alemán y norteamericano, sino que era un verdadero científico, un maestro cabal, además de ser un excelente y honesto administrador del escaso presupuesto universitario.

Con el realismo, concreto y práctico, muy anglosajón que lo animaba, orientó la vida académica sobre cuatro pilares básicos: 1) el conocimiento de la realidad de la región cuzqueña y de los problemas de la urbe Imperial; 2) la enseñanza de métodos de investigación modernos y eficaces; 3) el trabajo de campo y el uso de la Estadística, porque en su opinión, no toda la verdad estaba sólo en los libros sino también en la observación, y 4) la elaboración cuidadosa de proyectos de investigación con el respectivo marco teórico. Todo esto fue una verdadera revolución contra la palabrería metafisica y hermética de los krausistas y la superación de la mirada hacia afuera de los estudiantes, haciéndoles preferir el estudio de lo cercano, concreto, cotidiano, vital y real.

Giesecke introdujo en sus enseñanzas la aplicación epistemológica del principio de Bain: 
La creencia es aquello sobre lo cual el hombre está preparado para obrar; definición de la cual según Peirce, el pragmatismo es corolario, y que se complementan con aquel principio tan famoso de William James: las verdaderas ideas son las que podemos asimilar, validar, corroborar y verificar (José Ferrater Mora).

Giesecke, en la Edad de Oro de la UNSAAC (1910-1940), fue capaz de ir más allá de la Proyección Social, formó una excelente biblioteca, obtenida en buena parte gracias al canje, para lo cual creó la Revista Universitaria, el órgano científico cuzqueño más importante del siglo XX y sobre la cual dos historiadoras italianas de la Universidad de Roma, bajo mi orientación personal, han elaborado una magnífica tesis acerca del período 1910-1977 de dicha Revista Universitaria, hace unos doce años. Integró la Universidad a la vida cotidiana de la Ciudad Imperial y, yendo mucho más allá de la Proyección Social, elaboró con sus alumnos el Censo del Cuzco de 1912.

Planificador insigne, proyectó las Facultades de Agronomía, Ciencias Económicas y Educación que sólo muchos años después de su retiro del rectorado, la Universidad logró concretar. Pero los dos logros más importantes de Giesecke fueron, primero: que gracias a sus enseñanzas y ejemplo logró formar una gran generación de cuzqueños que después irrumpiría en la vida regional y nacional, la famosa Escuela Cuzqueña, bautizada así por Francisco García Calderón en el diario "La Nación" de Buenos Aires, cuando la cultura argentina estaba tan ligada al Cuzco. Segundo, que puso en forma a la UNSAAC para que esta siguiera funcionando eficientemente por varios lustros más allá de su retiro, promoviendo el estudio de su historia. Fue un modernizador insigne; es cierto que fue impuesto desde Lima y que ni siquiera era peruano, pero eso no impidió que fuera el gran inspirador de la Edad de Oro de San Antonio Abad, cuya presencia e influencia nacional todavía nadie ha podido superar porque entre 1910 y 1930 la UNSAAC sería la universidad líder en el Perú, compitiendo con San Marcos. A sus aulas acudirían estudiantes foráneos atraídos por su progreso y su nueva estrategia académica; entre ellos, José Luis Bustamante y Rivero y Víctor Raúl Haya de la Torre, estudiantes de la UNSAAC en 1917-1918. José Carlos Mariátegui elogiaría el espíritu democrático y renovador de San Antonio Abad en los Siete Ensayos en 1928.

Pero el logro históricamente más trascendental de Giesecke, no sólo fue el darle el derrotero preciso a Bingham para llegar a Machupicchu, en 1911; sino el haber educado y formado a una generación de cuzqueños que crearon bajo su sombra las grandes ideas políticosociales que sacudieron el país entre 1920 y 1950. Esas ideas fueron el Indtgenismo que fue madurado, gestado y lanzado al país por don Luis E. Valcárcel, que migró a Lima en 1930 para remplazar a Julio C. Tello en la dirección del Museo Nacional, y quien proyectó las ideas andinas sobre el campesino heredero de los Incas, al panorama peruano, dando origen después de su ingreso a San Marcos a la Etnología, a la Etnohistoria y a la ONG más importante: El Instituto de Estudios Peruanos, propagando las historias cuzqueñas a todo el Perú y a los demás países andinos. Valcárcel fue el gran propagandista de las ideas cuzqueñas a toda la región andina y a la propia capital criolla, el gran universalizador de las ideas cuzqueñas.

Luego José Uriel García, su émulo, amigo y rival, escribiría el libro más influyente de esta época (1930), El Nuevo Indio, con el cual lanzó mucho antes de Bourricaud y de Aníbal Quijano los primeros indicios de un cambio social y cultural espontáneo en la base social y en el movimiento demográfico a partir de 1940 que estos han llamado cholificación y García, neoindianismo, fenómeno mediante el cual los campesinos andinos, no sólo del Cuzco sino de toda la Sierra, migrarían a la Costa y a Lima y allí sufrirían un proceso de aculturación por el cual se convertirían en habitantes precarios, de los extramuros y goteras de la Urbe Virreinal, generalmente desérticos, fundando un nuevo tipo de asentamiento urbano republicano, las llamadas barriadas por José Matos Mar. Así, las ideas de Valcárcel y García, acentuadas por la explosión demográfica que ellos no previeron y por la migración interna masiva y revolucionaria en lo demográfico, han producido que el Estado Virreinal, costeño y palaciego de Lima, sea hoy un Estado Desbordado por las masas migrantes de una sociedad nacional emergente que supera ya la idea del desborde popular de hace más de 25 años y que proviene del mismo Matos Mar, parece que con la ayuda del extinto Fernando Fuenzalida. Hoy, Matos Mar habla adecuadamente de las cuatro Limas diferentes, una Lima burguesa tradicional, rodeada de tres Limas populares y emergentes, en las cuales hay una extraordinaria complejidad social y un cambio económico que no puede negarse, si recordamos que esos migrantes proceden de campesinos humildes de la Sierra y la Costa. De modo que estas ideas de García sobre el 
nuevo indio y la masificación de su presencia son ciertas. Precisamente, sobre ese fenómeno, Carlos Araníbar dijo hace más de una década, con gran poder adivinatorio, que el siglo XXI, en el Perú sería el siglo de las masas.

La tercera idea que surgió fue la del Descentralismo y Regionalismo, bajo el liderazgo político de un discípulo de Giesecke, Francisco Tamayo Pacheco y de los escritos del geógrafo y economista puneño Emilio Romero Padilla que salian a desafiar el centralismo absorbente de la Lima Virreinal y al cual le hicieron frente los 33 diputados descentralistas del Congreso Constituyente de 1931, arrancando del poder limeño la creación de los Consejos Departamentales que las dictaduras de Benavides y Prado pusieron en la congeladora. Sólo en 1950 se promulgó la Ley 11551, por iniciativa de Francisco Tamayo, que hizo aprobar con dicha ley el primer organismo descentralizado del Perú, la Junta de Reconstrucción y Desarrollo Industrial del Cuzco y que luego se amplió con la CRIF en 1957, mediante la Ley 12800 con el aporte.jurídico de Rodolfo Zamalloa Loayza, mi querido maestro, leyes con las cuales se pudo reconstruir el Cuzco en cinco años después de ser asolado por el terremoto del 21 de mayo de 1950; simultáneamente se abrió el camino para la aparición de las Corporaciones Departamentales en los gobiernos de Belaúnde Terry, como un primer intento del descentralismo. Luego Alan García formó y creó regiones con nombres históricos, pero que tenían el lastre del asambleísmo y por fin Toledo se fue al otro extremo, convirtiendo todos los departamentos en regiones, aunque su territorio y población fueran minúsculos. Pero esta idea del regionalismo y la regionalización surgió de San Antonio Abad, a través de la Logia Federalista que formaron Samanez Ocampo y Francisco Tamayo; mientras el resto del país se mantenía en la ataraxia, cuzqueños y puneños, como Tamayo, organizaban el Partido Descentralista en todo el Sur Andino y Emilio Romero Padilla, escribía el libro teórico sobre el Descentralismo. Tamayo siguió el modelo de la TVA norteamericana (Tennesy Valley Authority) y fue uno de los primeros en captar la idea del desarrollo en 1950, del seno de la ONU y de la CEPAL.

Hoy se hace dificil comprender cómo un puñado de profesores (20 o 30) y 165 alumnos, en 1922, con una subvención escasa, sin ninguna ayuda extranjera ni de ninguna ONG, que felizmente no habian proliferado todavía como hongos después de la lluvia, pudieran realizar tan vasta tarea intelectual, social y modernizadora y práctica, que dado lo marginal del Cuzco de entonces, resulta casi sobrehuman. La única explicación posible está en su entrega apasionada y desinteresada a la cultura y a la ciencia. $\mathrm{Su}$ mística de trabajo y de esfuerzo que venció al dolce farniente provinciano. Los impulsaba la llama de una vocación y no el simple afán por una sinecura. Su gran capacidad de trabajo y lo que hicieron, resulta de su enorme dimensión de entrega a un ideal, y a su fe y amor por el Cuzco y el Perú.

\section{XIV}

En los últimos años de la década del 30 aparece la Generación del 27 que según José Carlos Gutiérrez Samanez la conforman los pintores Mariano Fuentes Lira, Francisco Olazo, Julio G. Gutiérrez y Alfonso González Gamarra y los literatos poetas e historiadores Román Saavedra, Segundo Jara Eguileta, Alfredo Yépez Miranda, Rafael Tupayachi, el químico Oswaldo Baca Mendoza y la abogada y poetisa Rosa Augusta Rivero. Aunque no aparece en el índice, pero sí en el capítulo quinto, con una referencia secundaria, creo que la persona más importante de esa generación es Humberto Vidal Unda 1906-1979.

Mientras los primeros son considerados muy importantes por el autor, por ser los introductores de un marxismo más sentimental que teórico y cuyo papel en la formación del Partido Comunista Peruano ha sido explicado, elaborado y analizado casi totalmente por Julio G. Gutiérrez y especialmente por Carlos Ferdinand Cuadros, en dos libros importantes. La personalidad de Humberto Vidal es la más significativa porque une a una formación filosófica más amplia, una intuición extraordinaria, una capacidad profética de vaticinio de los acontecimientos futuros en el Cuzco del siglo XX. Porque él creó la Hora del Charango, a través de las ondas de Radio Cuzco, e impulsó y proyectó la música indígena y mestiza, por primera vez, a los medios de comunicación de masas, contribuyendo como ninguno a la difusión de la música andina a nivel regional y nacional electrónicos. La unión entre la música de las masas campesinas y los medios electrónicos modernos fue fundamental y eso lo hizo Vidal y resultó mucho más importante para el cambio social que la escasa influencia de Pututu y Kuntur, para el cambio de mentalidad y sensibilidad hacia lo andino. 
Igualmente, las masas cuzqueñas no tenían símbolos de identidad y Humberto Vidal, una tarde bohemia de mayo de 1943, en el almuerzo del Sindicato de Periodistas del Cuzco, del cual era miembro, lanzó y alumbró una idea sencilla pero inspirada y genial: el Cuzco debería tener su día, era necesario consagrarle una fecha. Luego, Vidal como Vicepresidente del Instituto Amęricano de Arte, organizó el primer día del Cuzco el 24 de junio de 1944, y junto con otros historiadores elaboró el guion original del Inti Raymi. Luego se dedicó 20 años a organizar la gran fiesta del Cuzco hasta convertirla en la fiesta más importante y popular de la ciudad y del Perú, creando un atractivo turístico extraordinario con más de setenta mil asistentes. Y no sólo desde un punto de vista social o estético, sino filosófico extraído de la raíz porque fue el precursor de una Filosofia Andina elucubrada en el Cuzco. Aunque no lo comprendieron en vida, sólo por eso Vidal es inmortal y una de las grandes figuras del Cuzco del siglo $\mathrm{XX}$.

\section{XV}

La lucha fundamental de la UNSAAC de 1945 a 1984 es la batalla de sus estudiantes por institucionalizar los principios de la Reforma Universitaria de Córdoba de 1918 y detener las ofensivas del Estado y de los adversarios políticos por destruirlos, sobre todo a la autonomía, la libertad de cátedra y el cogobierno.

La primera etapa se abre con la promulgación de la Ley $\mathrm{N}^{\circ} 10555$, aprobada por un parlamento de mayoría aprista. La aplicación de ésta resulta en la elección del rector Alfredo Yépez Miranda, quien dominado por el FRU, comete algunos desatinos, incluido el alejamiento de un maestro tan genial como José Uriel García que es hostilizado por un pequeño grupo de estudiantes por su color político y que tiene que trasladarse a San Marcos y al Senado, invitado por la universidad limeña. Luis Nieto, el año 2011 en el colofón al libro El Nuevo Indio de García, hace esta revelación desconocida. Todo este período de dictadura del FRU termina abruptamente con el golpe de Estado de Odría y con la segunda intervención por parte del Gobierno, en noviembre de 1948, siendo nombrado como rector interventor el doctor Rafael Aguilar Páez, gran poeta modernista que se ve obligado a alejar de las aulas a casi todos los catedráticos apristas y perseguir a los estudiantes del FRU.
Luego, la Universidad recupera en parte su autonomía a partir de 1951 con el gobierno rectoral del doctor Luis Felipe Paredes, maduro y cazurro epígono de la generación de la Escuela Cuzqueña. Vale decir que en 1957, en ninguna universidad peruana, ni siquiera en San Marcos existía el cogobierno. Pero los estudiantes del FRU en el Cuzco obtienen una gran victoria con la elección de un líder excepcional, el pequeño y corajudo Mario Cama Miranda. De pronto, el 26 de setiembre de 1957, después de varios días de forcejeo por parte de los profesores anti reformistas y superando las limitaciones prohibitivas de la Ley General de Educación de 1941, en una magna asamblea multitudinaria apoyan y logran hacer aprobar la introducción del cogobierno en los claustros de la universidad cuzqueña, rompiendo así con el tabú que pesaba contra este. ¿Cómo reaccionó el gobierno de Prado, cuyo ministro de Educación Pública era don Jorge Basadre, el gran historiador de la República y viejo partidario de la Reforma desde 1920? Lejos de reprimir el estallido reformista que venía de abajo en el Cuzco y que une a profesores independientes de gran prestigio y a los estudiantes del FRU, sorprendentemente los reconoce y los apoya. El 5 de octubre de 1957, Basadre había expresado ya la actitud del gobierno de Prado, al responder al oficio del Presidente de la Junta Reorganizadora del Cuzco, doctor Sergio Quevedo Aragón (Premio de Fomento a la Cultura), que le comunicaba su asunción al gobierno universitario del Cuzco con el apoyo y el voto de los estudiantes, que tomaba nota del oficio y formulaba votos por el progreso y la eficiencia de la muy ilustre Universidad del Cuzco (Jorge Basadre). Con esta actitud del ministro, el movimiento reformista del Cuzco quedaba santificado y la UNSAAC era, otra vez, la precursora de un movimiento nacional que prendió la chispa que se extendería después a las demás universidades peruanas. El Estado no sólo aceptó y toleró el movimiento cuzqueño del 26 de setiembre de 1957, sino que más aún se inspiró en él y lo legitimó en 1960, al promulgar la Ley $\mathrm{N}^{\circ} 13417$, que aceptó e introdujo el cogobierno en todas las demás universidades del Perú. El 26 de setiembre de 1957, constituyó un hito histórico en la lucha por la Reforma Universitaria en el Perú y abrió el más largo período de vigencia de un cogobierno democrático en la Universidad Peruana y en nuestro país, en lo que va del siglo XX. Es decir, doce años. A mí me cupo el honor de recibir el encargo del gobierno estudiantil de Mario Cama, para hacer conocer el movimiento cuzqueño en 
San Marcos y en las demás universidades limeñas. Así pronuncié una conferencia en el Salón General de la Facultad de Letras de San Marcos en la Casona en mayo de 1958, y los estudiantes sanmarquinos, se mostraron incrédulos de que en la UNSAAC, ya hacía ocho meses que imperaban los principios de la Reforma Universitaria, pues estando como estaban las universidades limeñas tan sometidas por la convivencia no podían creer en el coup de etat cuzqueño.

\section{XVI}

La dictadura militar de Velasco expidió, en febrero de 1969, el Decreto Ley $N^{\circ}$ 17437, que suprimió las conquistas de la Reforma Universitaria y estableció una universidad cuasi castrense, sin cogobierno, sin voz de los alumnos y con el poder concentrado en el rector en forma vertical como si fuera la Universidad un cuartel. Además, introdujo experimentos extraños a la tradición antoniana de trescientos años, como los Estudios Generales, el departamentalismo y el sistema de créditos. El rector elegido contó desde el principio de su régimen con la oposición de un buen sector de docentes, de los estudiantes y los empleados no docentes, los mismos que sólo después de dos años de soportar este sistema se levantaron en un movimiento de lucha de 45 días tensos y dificiles que comenzaron el 4 de agosto de 1971 y terminaron el 15 de setiembre de 1971, lapso durante el cual tomaron los locales universitarios y los mantuvieron en sus manos. Finalmente, el 15 de setiembre de 1971 , el CONUP, representado por Mario Samamé Boggio y Efraín Morote Best, estableció en la UNSAAC, el Gobierno Tripartito, extendiendo este a los empleados y restableciendo el cogobierno de los tres estamentos, quedando anulado y derogado de hecho, en el Cuzco, el Decreto Ley 17437, el 15 de setiembre de 1971. Yo integré este gobierno tripartito como Director Universitario de Evaluación a los 34 años y era el único abogado de dicho organismo y el más joven del mismo.

Así el Cuzco fue la primera de las universidades peruanas que dio el ejemplo de implantar la Reforma Universitaria en plena dictadura militar e inspiró al gobierno de Velasco para que reconsiderara su política anti reformista y recogiera la experiencia cuzqueña en el sistema de gobierno universitario en el Decreto Ley $\mathrm{N}^{\circ}$ 19326, que recogía el cogobierno para las diversas universidades nacionales y privadas y aún para el máximo organismo nacional: el CRESU, que remplazaría al odiado CONUP y que disponía que este Decreto Ley $N^{\circ} 19326$ fuera reglamentado por una Comisión Estatutaria Nacional, de mayo a setiembre de 1972, en Lima y en cuyo seno participarían las autoridades universitarias, los profesores, los alumnos y los trabajadores no docentes, elegidos por sus bases en elecciones democráticas. El teórico de este Decreto Ley $\mathrm{N}^{\circ}$ 19326 era el filósofo Augusto Salazar Bondy, un gran pensador, con gran experiencia especulativa en el terreno del pensamiento teórico, alter ego y eminencia gris del General de División Alfredo Carpio Becerra, Ministro de Educación, pero sin experiencia alguna en el gobierno directo de una Facultad o Universidad, de modo que era un sabio pero sin experiencia de la vida cotidiana y más aun de la política criolla. El resultado fue que la CEN resultó un Campo de Agramante, una olla de grillos, en la cual convivieron los sectores más radicales de la izquierda y de la derecha, desde el propio Sendero Luminoso de Ayacucho hasta el Opus Dei de Piura y las tendencias apristas, marxistas y derechistas tradicionales, que no entendieron desde el principio que se les había reunido para reglamentar una Ley dentro de los cauces que dicha norma establecía, conforme a la Constitución.

El que esto escribe fue elegido unánimemente como Presidente de la CEN, a los 35 años y después de mi renuncia, Hugo Flórez Ugarte, también del Cuzco, fue elegido vicepresidente. Cuando el sector del CEN que orientaba Odón Espinoza, trató de elaborar un proyecto de Estatuto que violaba claramente los principios de la Reforma, principalmente la libertad de cátedra y quería establecer un sistema burocrático, engorroso y caro que chocaba con el Decreto Ley que era funcional, vimos que era indispensable una asesoría jurídica y constitucional y logramos que el abogado cuzqueño, doctor Valentín Paniagua Corazao, jurista con gran experiencia constitucional, nos diera una asesoría jurídica de su especialidad llegando ambos como abogados, después de un largo diálogo de muchas horas, a la conclusión de que este proyecto de Estatuto violaba numerosos artículos del Decreto Ley N 19326 porque encerraba una contradicción insalvable en su filosofia sustentadora. Era un matrimonio morganático, totalmente inestable desde su raíz, entre pensamientos y filosofias y praxis totalmente disímiles; en total, dos conjuntos de principios que impedían construir una síntesis viable y eran por 
el contrario totalmente inconciliables, porque eran en el fondo un galimatías o chaner entre el espíritu de la Reforma Universitaria de Córdoba y el modelo norteamericano de universidad traído de fuera por Salazar Bondy y el choque entre ambos producía que nos podíamos estrellar contra un principio constitucional fundamental: las leyes se reglamentan sin alterarlas ni desnaturalizarlas, ni modificarlas, ni tergiversarlas. Como el Estatuto debía ser aprobado por la dictadura militar, mediante un Decreto Supremo, era prácticamente imposible que el ministro castrense de Educación, expidiera dicho Decreto a favor de una norma ilegal, pues la más elemental aplicación del principio de casación y del examen crítico-jurídico del estatuto aprobado por la CEN, llevaría a su desaprobación y nulidad, declarada por la Dictadura Militar, cosa que ocurrió finalmente porque el Gobierno Militar y los medios de comunicación de masas agitaban, adrede, las contradicciones en el seno de la CEN. Así, se perdió la brillante oportunidad de cambiar al opresivo CONUP por el democrático CRESU y los sectores castrenses más radicales de la dictadura se salieron con el gusto de hacer cumplir lo que establecía una norma transitoria del Decreto Ley $\mathrm{N}^{\circ} 19326$. En caso de que no se aprobara el Estatuto, por ser ilegal, seguiría vigente el Estatuto General de la Universidad Peruana (EGUP), que era el que había reglamentado el reaccionario Decreto Ley $N^{\circ} 17437$, hasta que se aprobara una nueva ley universitaria. $Y$ así se dio el caso incréble en la universidad peruana, de que un reglamento de una ley ya derogada siguió rigiendo el sistema universitario, desde fines de 1972, hasta diciembre de 1983, en que se aprobó y promulgó la ley Sánchez $\mathrm{N}^{\circ} 23733$. El sistema universitario, incluida la UNSAAC, resultó viviendo once años, bajo las normas de un reglamento de una ley ya derogada, habiendo existido el sistema universitario peruano once años al margen de la ley, en la más absoluta ilegalidad, caso único en la historia universitaria del mundo.

Esto es lo que Valentín Paniagua y yo tratamos de evitar con la advertencia jurídica a la CEN de este peligro inminente y exhortamos a sus miembros a lograr el diálogo, la comprensión, el espíritu jurídico y el gran ideal de la universidad democrática, teniendo en cuenta la oportunidad que nos brindaba el Decreto Ley 19326, pero lejos de oírnos, una momentánea mayoría obnubilada, aprobó un estatuto ilegal y absurdo que cuando lo entregaron a los militares, terminó en un basurero del despacho ministerial como un papel de desecho, inútil. Los responsables de todo esto jamás asumieron su culpabilidad. A veces, la pasión política y el sectarismo amoscado y áspero conducen a que se nuble la luz de la razón. Con razón mi maestro Basadre decía que el Perú era el pais de las oportunidades perdidas.

\section{XVII}

El Gobierno Tripartito presidido por Isaac Velasco Quintanilla, se tornó en un grupo muy débil, dominado por un grupo de alumnos que vivían el desequilibrio y el frenesí de la Revolución Cultural en China y ciertas consignas de la banda de los cuatro, que hoy han sido totalmente olvidados en la potencia oriental. No olvidemos que vivíamos todavía bajo la atmósfera de Mayo del 68 en París y que habían decidido acabar con la rieja cultura feudal; es decir, con la antigua Facultad de Letras y Ciencias Humanas por lo que yo no volví de Lima hasta bien finalizado el año 1972. El año 1973, este clima de abuso inhumano de docentes, trabajadores y dirigentes llegó a su clímax el 26 de noviembre de 1973 cuando de modo misterioso el Palacio del Marqués de Valle Umbroso situado en la calle Marqués y local del odiado SINAMOS se incendió, junto a una de las constantes algaradas de los agentes de la banda de los cuatro. En 1974 y después de la ocupación militar del Claustro, condujeron a la tercera intervención de la UNSAAC por el Estado, mediante la Resolución $\mathrm{N}^{\circ}$ 1531-74 del CONUP que determinaba la total reorganización de la universidad cuzqueña, disponiendo la inestabilidad de sus docentes en sus cargos y toda esta tropelía cometida por un organismo llamado COGOIRE, presidido por el ingeniero Hugo Pacheco Garmendia, conocido reorganizador de universidades del CONUP. El pretexto para esta intervención fue el indicado incendio del Palacio del Marqués de Valle Umbroso, en la calle Marqués de la ciudad del Cuzco, el 26 de noviembre de 1973, siniestro que ha quedado en el misterio y que fue el gatillo que esperaban las fuerzas reaccionarias del CONUP para disparar contra San Antonio Abad y que ocasionó profesores despedidos, juicios penales a diestra y siniestra y una reorganización académica realizada por colaboradores y técnicos de Lima que trajo Pacheco, a los cuales escuchó hasta el punto de extinguir la antigua Facultad de Letras y Ciencias Humanas, principalmente, las especialidades de Filosofia y Literatura en 1974, con lo cual desapareció la Facultad y los estudios de la medalla azul, con que había 
nacido la UNSAAC, en 1692, matando así a las Humanidades en un medio social como el Cuzco en que había tanta creatividad literaria desde hace siglos. Igualmente minimizó a la especialidad de Historia. Así la UNSAAC de universidad humanística, se convirtió en tecnológica de tecnología de bajo voltaje en la enseñanza e investigación tecnológica casi insignificante. Los asesores limeños de Pacheco lograron así, eliminar las Humanidades en 1974 y parte de 1975; la UNSAAC continuó rigiéndose por autoridades designadas por el CONAI hasta la promulgación de la Ley N 23733 de 1984 (Ley Sánchez) que es la vigente hasta hoy. Pero desde 1972 hasta 1984, la universidad cuzqueña y sus similares del resto del país, continuaron rigiéndose por el EGUP, el reglamento de una ley derogada doce años antes, en 1972; caso absurdo e insólito en toda la historia dela universidad peruana y que nunca ha ocurrido en ninguna otra parte del mundo, gracias al cual los militares manejaron el sistema universitario a su gusto y que constituyó un caso de intervención universitaria único en Sudamérica, sólo propio de una dictadura autocrática como la de Velasco y Morales Bermúdez.

\section{XVIII}

Vamos a cambiar totalmente de óptica en este discurso para conocer y valorar la intervención, no del Estado, sino la de algunos estudiantes de la Universidad de San Antonio Abad y de profesores-abogados de su claustro a favor de la transformación social de la estructura agraria arcaica del departamento del Cuzco, entre 1958 y 1964, verdadera epopeya en la cual la UNSAAC logró su mayor hazaña de proyección social revolucionaria, en la cual los románticos sindicalistas, inspirados dentro las diversas orientaciones del marxismo y con el aliento radial y propagandístico de la Revolución Cubana, transformaron la estructura agraria de La Convención y Lares y luego se expandieron por Anta, el Valle Sagrado, Paucartambo, Quispicanchis y Canchis y que ha sido retratado a grandes rasgos por Hugo Neira en su libro Cuzco, Terra o. Muerte.

Así como la UNSAAC de la segunda década del siglo XIX, había luchado sacrificada inútilmente por la Independencia; la troika cuzqueña compuesta por la FUC, la FDCC y la FTC, todas inspiradas en el marxismo de la Revolución Cubana, destruyó el sistema de hacienda de La Convención y Lares y lo trastornó seriamente en la parte serrana del departamento del Cuzco, produciendo una Rebelión Campesina, mostrando al Estado Limeño que el sistema de hacienda en el Cuzco era ya indefendible y que venían corrientes del exterior en pto de la Reforma Agraria. Estas dos corrientes convergentes hicieron que la labor sindicalista revolucionaria de los dirigentes estudiantiles de diversas tendencias dentro del marxismo, fueran decisivas para esta Rebelión Campesina, cuyas conmociones llegaron a la Virreinal Lima a través de las comunicaciones de las autoridades departamentales y de la prensa que actuó como el fuelle del herrero, exagerando los hechos; y obligando a la Junta Militar de Gobierno a dictar los Decretos Leyes $N^{\circ} 14238$ y No 14444 a fines de 1962, y marzo de 1963, que legalizaron la revolución desde abajo hecha por los arrendires y los agitadores universitarios y abogados de San Antonio Abad que habían creado el clima y los hechos para que esta revolución agraria se consumara al margen de las leyes del Estado Peruano. Como dice Fioravanti esta rebelión campesina fue el mayor movimiento de masas campesinas, desde José Gabriel Tupa Amaru, 180 años antes, y por lo tanto la más importante de los últimos doscientos años.

Esta rebelión campesina tuvo agentes dinamizadores universitarios sin los cuales, tal vez no se hubiera producido, porque vencer la ataraxia del sistema de hacienda, exigía una acción política sagaz, inteligente y enérgica, por parte de los activistas estudiantiles.

Entre esos estudiantes y luchadores sociales que causaron la revolución agraria se puede citar a: Hugo Blanco Galdós, Vladimiro Valer, Fausto Cornejo, Héctor Loayza, Raúl Medina de Latorre, Roberto Soto Venero, Hugo Miranda Bernal, Rubén Acurio Moreno, Urbano López, Calixto Coanqui, Angel Avendaño Farfán, Darío Acurio Moreno, Eugenio Palma. La decisión estratégica y las tácticas de agitación y propaganda estaban en manos de Hugo Blanco y los demás eran miembros del aparato agitador anti gamonal que cumplían funciones de activistas y organizadores de sindicatos. Paralelamente, los abogados marxistas de la universidad, prestaban asesoría jurídica y política, y entre ellos se encontraba el inteligente precursor en el estudio de la realidad convenciana: Carlos Ferdinand Cuadros, así como Estenio Pacheco Tagle, Víctor Angles Vargas, Carlos L. Valer Portocarrero, Alfredo Muñiz, Ernesto Quispe Ledesma, en Quillabamba, Pílade Tupayachi, etc. Pero anteriormente, en 1958, ya algunos dirigentes 
de la FTC, de orientación moscovita como José Calvo Bohorquez, Emiliano Huamantica, Pascual Montaño y Alfredo Somocurcio, habían estado organizando sindicatos en el valle de La Convención y en Lauramarca. Los periodistas cuzqueños y limeños le adjudicaron toda esta labor colectiva, en que convergían varias de las tendencias de izquierda (del PCP, el trotzquismo y el MIR) a una sola persona: Hugo Blanco, creando la leyenda de autor único de la Rebelión Campesina, de guerrillero invencible y de héroe popular, creando un mito. Quien le regaló esta fama a Blanco fue el periodista de La Prensa de Lima, Germán Alatrista Bustamante, fabricando un personaje irreal y creando su leyenda de líder absoluto de la rebelión campesina cuzqueña. Como dice Fioravanti, la figura de Blanco terminó opacando a los legítimos activistas de la lucha anti terrateniente que fueron los auténticos dirigentes campesinos: los arrendires y colonos de las haciendas. La Rebelión Campesina Cuzqueña fue la única que nació en una universidad y que utilizó principalmente estudiantes y su acción revolucionaria, logró triunfar y cambiar la historia del Perú, porque sin este prolegómeno, la Reforma Agraria, donde yo colaboré en 19641965, se hubiera atrasado décadas o no hubiera sido posible. Este es el máximo galardón de la UNSAAC en el siglo XX, por encima de la Alianza para el Progreso de Kennedy, porque fue más eficaz que esta. Estos activistas estudiantiles y los abogados universitarios fueron perseguidos, apresados y confinados en la Isla del Diablo, del SEPA, tanto por el ministro castrense, como por el Ministro de Gobierno de Belaúnde: Juan Languasco de Habich y pagaron un alto precio con su prisión en la selva, por su emoción social a favor de la inclusión de los marginados mediante la lucha por la tierra.

\section{XIX}

Es muy dificil hacer un balance de la producción intelectual de la UNSAAC en los siglos XIX y XX, y respecto al XXI, resulta demasiado temprano para identificar lo significativo. Nosotros además pretendemos algo relativamente diferente pues no queremos tocar sólo a los profesores, científicos e investigadores locales, confinados entre los muros de la UNSAAC, sino que nos proponemos incluida todos los antonianos que estudiaron en nuestra Alma Mater, pero que han trabajado en Lima o en el resto del país en cargos importantes, científica o profesional, aunque no hayan residido permanentemente en el Cuzco. Por eso señalaremos a funcionarios públicos importantes, magistrados de alto nivel, diplomáticos, profesores y autoridades máximas de otras universidades pero formadas en San Antonio Abad, todos ellos antonianos. No proponemos un listado de personas ni una suma de personas y obras como parece lo intentó otro historiador. Una historia es historia de procesos y de problemas y no un ¿Quién es quién?

Confesamos que tal vez cometamos omisiones involuntarias al realizar un balance que no pretende ser totalizador sino de lo que nos parece más significativo o destacado. Por eso pidiendo disculpas a mis maestros, colegas y amigos, sólo tocaré aquellos nombres de antonianos que tienen un aporte en el Guzco o fuera de él, hayan profesado o no en la UNSAAC, siendo su aporte profesional o científico; pero que han pasado el umbral histórico. $\mathrm{Mi}$ relación no es taxativa sino solamente enumerativa y naturalmente imperfecta y por eso pido perdón de antemano a mis oyentes y lectores.

En el terreno de la Antropología Andina, considero que destacaron Víctor Navarro del Aguila, Efraín Morote Best, Oscar Núñez del Prado Castro, Sergio Quevedo Aragón y Luis Barreda Murillo, ya extintos. Entre los que se encuentran activos con brillo creador están, ante todo Jorge Flores Ochoa, uno de los mejores antropólogos peruanos y uno de los pocos de prestigio internacional que con sus 4 o 5 libros, publicados con el auspicio del BCP y con el concurso de cuatro o cinco especialistas que forman su equipo ha logrado crear un rico material sobre el Cuzco, a más de sus Pastores de Paratía y sus trabajos sobre la incanidad. Ricardo Valderrama Fernández y señora, iniciadores de la tradición e historia orales en el Cuzco con su biografia de Condori Mamani y su libro Nosotros los Humanos; Jorge Villafuerte Recharte, Abraham Valencia, con sus investigaciones sobre la religiosidad en el Cuzco, David Ugarte Vega Centeno, eficiente funcionario y preocupado sobre Machupicchu, Italo Oberti, Juan Víctor Núñez del Prado, Raymundo Béjar, con su aporte sobre el Qoricancha, Fernando Astete, y Julinho Zapata, conocedores de Machupicchu y desde luego, Oscar Paredes Pando, uno de los pocos investigadores sobre la Amazonía, además de sus aportes históricos sobre la historia de la UNSAAC.

Entre los que se dedicaron al estudio de la realidad cuzqueña e Inka a través del marxismo, 
hay que considerar los aportes de tres estudiosos de Marx, como Carlos Núñez Anavitarte con sus estudios sobre los Inka; Carlos Ferdinand Cuadros con sus trabajos teóricos sobre la universidad democrática y su invalorable tesis sobre el arriendo en La Convención. También es digno de notar el trabajo sobre el "Cuzco Rojo" de Julio G. Gutiérrez, antiguo alumno de San Antonio Abad.

En el área de la Ciencia Natural cabe señalar a Antonio Lorena, Fortunato L. Herrera, Oswaldo Baca Mendoza, César Vargas Calderón, Ismael Zevallos Bendezú, Felipe Marín Moreno, Oscar Blanco Galdós.

En el área de la Historia hay una relación realmente larga desde la colonia. El Inka Garcilaso de la Vega, (el padre de la Historia Cuzqueña) Diego Esquivel y Navia, José Benigno Mesa, José Manuel Váldez y Palacios, Fernando Pacheco, Luis E. Valcárcel, José Uriel García, José Gabriel Cosio, Luis Felipe Aguilar, César Antonio Ugarte, Julián Santisteban Ochoa, Jorge Cornejo Bouroncle, Luis Vélazco Aragón, Horacio Villanueva Urteaga, Luis A. Pardo, Víctor Angles Vargas, Manuel Jesús Aparicio Vega, José Tamayo Herrera con su Revista Teqse; Teófilo Benavente Velarde, con su Historia de la Pintura Cuzqueña Colonial. En el siglo XII destaca la obra histórica de Elizabeth Kuon Arce, sobre el Cuzco y Buenos Aires, Eduardo Zegarra Balcázar, con su labor de colaboración oral sobre los tiempos contemporáneos para nuestro libro Las Elites Cuzqueñas, Donato Amado, Francisco de Goya Benavente, Oscar Paredes Pando con su reciente historia de la universidad, el actual rector Germán Zecenarro Madueño con su Historia Local sobre Saylla, Eleazar Crucinta, especialista en Historia del Arte que ha escrito la biografía de Mariano Fuentes Lira y el Libro de Oro de la Escuela Nacional de Bellas Artes.

En el campo filosófico destacan el maestro Humberto Vidal Unda, genial creador del Día del Cuzco y del pensamiento Inca; Alberto Delgado Díaz, poeta insigne y gran conocedor de Edmund Husserl; Antonio Astete Abrill, gran conocedor de Spengler; Daniel Castillo Manrique, experto en la moral del bushido; Hugo Flórez Ugarte, Armando Barrionuevo Sánchez, José Tamayo Herrera, editor de la Revista Filosófica Teqse, Moisés Tello Palomino y Max Gotardo Aguirre Cárdenas, editor de la revista filosófica y antropológica: Ande y autor de un libro de historia local sobre Vilcashuamán y Cangallo, Ayacucho.
En la creación literaria y poética destacan Rafael Aguilar Páez, Alberto Delgado Díaz, José Gabriel Cosio; Luis Nieto Miranda, autor de la letra del Himno al Cuzco y gran animador cultural; Gustavo Pérez Ocampo, Alfredo Yepez Miranda, Andrés Alencastre Gutiérrez, Enrique Rosas Paravicino, Ángel Avendaño Farfán, gran poeta y novelista y cuya novela Los Cuervos de San Antonio es un retrato irónico y mordaz de un momento histórico de la historia de San Antonio Abad entre 1971 y 1974; Luis Nieto Degregori, gran cuentista y novelista; Mario Guevara Paredes, gran animador de la Literatura en su revista Siete Culebras, Patricia Marín Casafranca, como gran periodista de la Webb, con Valicha y Hugo Bonett, gran animador de la revista El Antoniano. Igualmente, destacan el ensayista sobre temas cuzqueños, Rossano Calvo y José Carlos Huayhuaca, cineasta y gran escritor, autor de la mejor biografia de Martín Chambi.

En el mundo del Derecho sobresalen Carlos A. Lira, César A. Muñiz, Enrique Holgado Valer, Rodolfo Zamalloa Loayza, Arturo Moscoso Serrano, Ernesto Valdivia Pezo, Gustavo Palacios Pimentel, Octavio Linares Alencastre, Lino Casafranca Gamarra y sobre todo, Carlos Ferdinand Cuadros y Villena, Olinto Vesco Zamalloa, Julio Salazar Flores, Teófilo Huayhuaca Saldívar, Leoncio Olazábal Feijoó, Edgar Chuquimia Cervantes, José Bẻjar Quispe, Aldo Estrada Choque, Pablo Ladrón de Guevara, Carlota Valenzuela de Puelles, Jorge Polo y La Borda González y Gloria Charca Puente de la Vega, David Pezúa Vivanco -Secretario Ejecutivo del Poder Judicial-, Julio González Montesinos, -gran especialista en Derecho Educativo-, Miguel Yépez Sánchez -Director de la Academia de la Magistratura y hoy Gerente Central de la Asesoría Jurídica del Ministerio Público (Fiscalía de la Nación)-, Carlos Santander Estrada, Augusto Ramos Zambrano, historiador y abogado, ex vicerrector de la UNTA y demás maestros, alumnos y profesionales destacados del Derecho en el Cuzco, en Lima y en la Universidad Peruana, procedentes de las aulas antonianas.

En el campo de la Economía y las finanzas destacan Efraín Gonzáles de Olarte, Raúl Galdo Núñez del Prado y Alejandro Contreras Sánchez.

\section{XX}

¿Qué le aguarda a San Antonio Abad en las próximas décadas del siglo XXI? La Universidad, gracias al canon ha logrado construir una 
estupenda infraestructura fisica. Hace cincuenta años, los alumnos recorríamos el Qalapampa del fundo Perayoq, que era escenario muy de vez en cuando de algunas aventuras báquicas o amorosas. Hoy el área está totalmente cubierta por edificios modernos de la Ciudad Universitaria. Así mismo, a partir de Perayoq y casi hasta San Jerónimo por la Avenida de La Cultura, hay varias decenas de edificios de seis a ocho pisos que constituyen el nuevo Cuzco, que se ha construido gracias a la globalización y a recursos como el oro de Madre de Dios, el turismo, el mercado negro del contrabando y aún la coca. Pero es innegable que el Cuzco es hoy una urbe cosmopolita y no la pequeña ciudad recoleta de 1950. En el 2010, ha tenido una población de 400,582 habitantes, diez veces más que en 1940, hace más de 70 años. Y ahora, así como hay cuatro Limas diferentes en la capital, hay varios Cuzcos diferentes a la ciudad histórica indo-hispana (Matos Mar, 2012). Cuzco es una gran ciudad milenaria con un gran pasado y un gran futuro.

Además, la revista Poder ha señalado que entre las seis próximas ciudades del Perú que van a despegar en los próximos cinco años, está el Cuzco, que tendrá para los próximos años un mercado de 627,840 millones de dólares y una PEA ocupada de $96.6 \%$.

El canon universitario que corresponde al Cuzco del año 2011 y que se pagará en el 2012, asciende a 85 millones de soles. Pero desgraciadamente, como se ha creado el 12 de noviembre del 2010, la Universidad Nacional Intercultural de Quillabamba, según manda la Ley del Canon, esta renta deberá ser dividida entre las dos universidades nacionales de la región, perdiendo la UNSAAC el $50 \%$ de lo suyo. Esto nos explica porque la UNIQ es sólo un germen pequeño y no pasa de una entelequia. La reciente noticia de que todo el gas del lote 88 de Camisea será para el Cuzco y para el Sur Andino, la región más pobre del Perú y los tremendos cambios que traerá este gas, la industria petroquímica, además del turismo cada vez más masivo, constituyen un desafio para la UNSAAC, pues no sólo deberá preparar los cuadros, y enseñar una nueva ciencia con la tecnología apropiada y moderna, sino proporcionar la investigación adecuada para aprovechar estos recursos. La misión de la ciencia no es sólo describir el mundo, conocer la realidad, sino principalmente transformarla. Estoy seguro colegas, hermanos, profesores y alumnos de la
UNSAAC que ustedes que han proporcionado una larga tradición de estupendas glorias, serán capaces de responder a este desafio porque ustedes son invencibles y vuest éxitos futuros con el gas, su industrialización, y un turismo cada día más moderno, y la agro tecnología resonarán en las edades futuras y serán como esas lámparas mágicas: alumbrarán sólo para la posteridad.

\section{XXI}

Después de este largo discurso, que ojalá no haya sido tedioso, los oyentes me dirán: ¿Qué puedes decir de tu generación?, ¿De aquellos jóvenes y hombres, que como decía Ortega, son tus coetáneos?

A mí, José Tamayo Herrera, el más modesto de mi generación nacida en 1936, me tocó por pura suerte, ser parte de una fraternidad o filiación muy especial, compuesta por grandes hombres, mis hermanos, en parte superiores a mí, en parte mis iguales, hombres brillantes y admirables, a los que la Enciclapedia Lexus llamó la de los grandes forjadores del Perú. Entre esos intelectuales, deportistas y políticos nacidos en 1936, figuran personajes de la talla intelectual del Premio Nobel, Mario Vargas Llosa, novelista y ensayista admirable, de fama universal y verdadero ciudadano del mundo. $\mathrm{Y}$ el peruano más planetario de nuestra literatura en esta segunda década del siglo XXI. A esta misma generación, pertenece Alejandro Olmedo Rodríguez, tenista extraordinario y campeón mundial de gran prestigio internacional, en su época, tal vez el deportista más cabal que ha tenido el Perú. Así mismo, es parte de esta generación de 1936, el gran crítico literario y ensayista: Antonio Cornejo Polar, autor de una amplia bibliografia, ya extinto, pero sin duda, el mejor crítico que ha tenido el Perú total. Otro personaje es Valentín Paniagua Corazao, nacido también en 1936, el político de esta generación, que significa un caso único en la historia de la República Peruana porque fue el único hombre de Estado que ejerció simultáneamente, la Presidencia de la República y la Presidencia del Congreso del Perú, dirigió un gobierno democrático, realizó elecciones intachables y limpias, después de la corrupción a que nos llevó la dictadura. ¿Qué diré yo de mí mismo sin caer en la inmodestia o en la llaneza? Solamente que he sido fiel a mi vocación de humanista por más de 60 años, porque me volqué a las letras a los 15 años y soy un hombre que ha transitado 
casi todos los caminos de las Humanidades, siempre fiel a ellas. Soy un historiador regional, dentro de los cánones de la Escuela de Annales. He tratado de renovar la enseñanza histórica para ponerla al día en la Universidad de Lima. Fui un estudioso de la creación poética, mediante el método fenomenológico, dirigido por José Gaos en Néxico y lo que me diferencia de mis colegas de la Generasión del 36, de Lexus, es que conozco los dos Perú en profundidad, que pertenezco a dos culturas igualmente primordiales: la criolla y la nativa y que conozco cabalmente la lengua de cada una. Como decía Porras, parte de mi vida he sido un hombre de la ciudad y del campo, pues desde los 18 años a los 33 he sido un pequeño empresario agroindustrial: produciendo licores de capulí y saúco, lacticinios y reproductores Brown Swiss. Debido a la temprana muerte de mi padre, y a diferencia de mis colegas, conozco los problemas prácticos tanto como los teóricos de la Economía y la Teoría Histórica. Cuando llegó la Reforma Agraria al Cuzco en 1964, puse mi experiencia adquirida en Bolivia, México, Cuba y Guatemala al servicio de esta transformación y dejé de ser empresario agrario para después dedicarme íntegramente a la UNSAAC. Soy pues un polígrafo, apasionado por la Teoría Histórica, porque he pensado que siempre la teoría precede a la historia. Soy el iniciador de la Historia Regional moderna en el Perú hacia 1965, cuando nadie hablaba de ella en el país y quise transformar la Giencia Histórica Peruana en la Universidad de Lima entre 1990-1994.

Soy pues un polígrafo que en sus primeros 25 años cultivó la poesía y estudió la Poética en el Perú y en México. He sido líder estudiantil y estudié también el Derecho, en el Perú y en el extranjero, pero lo que más me llamó la atención fue la Teoría Histórica y la convicción de que el historiador, si es honesto consigo mismo, puede llegar a la verdad. Que no todo es ficción en el mundo de las letras y las humanidades, que siempre hay una verdad verde, bella y verídica, como decía el poeta Juan Carlos Galdo. Y para concluir, sólo diré, que pertenezco al fenómeno demográfico más importante del Perú en el siglo XX, he sido y soy un migrante, igual que millones de peruanos, que todavía tiene la nostalgia de su lar, del Cuzco Imperial y del Valle Sagrado, y que el motor fundamental de mi obra histórica ha sido el de intentar curar la nostalgia de mi tierra con el cultivo de las Humanidades, especialmente la diacronía. Que pese a mis cuarenta años de ausencia, sigo hablando y cultivando el quechua y escribiendo poemas en ese idioma y en quechuañol y que es eso lo que me distingue y caracteriza respecto a mis compañeros de generación: tres arequipeños y dos cuzqueños.

\section{XXII}

Dedico este discurso a dos hombres excepcionales que me ha tocado conocer: a Daniel Estrada Pérez, mi alumno más distinguido en el curso de Historia Crítica Nacional, y a Valentín Paniagua Corazao, mi amigo íntimo de la juventud y de la lucha universitaria, con el cual conversábamos por las calles del Cuzco durante la noche, sobre todos los asuntos divinos y humanos, en caminatas interminables hasta pasada la media noche.

Durante el tiempo en que he participado, directa o indirectamente en la Historia Cuzqueña y en la de San Antonio Abad, he conocido a esos dos hombres excepcionales: mi alumno predilecto, Daniel Estrada Pérez, tres veces Alcalde del Cuzco, tal vez el mejor alcalde del siglo XX, parlamentario Ilustre y político presidenciable, y gran mecenas de los intelectuales, mi alumno de Historia Crítica Nacional, en una promoción de estudiantes extraordinarios. De otro lado, el destino me hizo amigo íntimo y compañero de aula de mi joven y brillante colega Valentín Paniagua Corazao, gran constitucionalista y mejor político, que en su breve período presidencial firmó, después de 14 años de espera, el contrato de Camisea que abrió al mundo esta riqueza cuzqueña que permanecía enterrada y muerta y que además hizo una política a favor de la UNSAAC, cediéndole la Casa del Marqués de Casa Concha que hoy atesora las obras de arte de Machupicchu, que nos ha transferido la Universidad de Yale. Igualmente, reivindicó para el INC, el local del antiguo Cuartel 27 de Noviembre, donde hoy funciona el Ministerio de Cultura, representado con brillo en el Cuzco por el Antropólogo David Ugarte Vega Centeno. Paniagua apoyó también los proyectos del Qapaq Nan y de Caral.

Rcivindico el papel de la Historia en la vida humana sobre los que la niegan como Fukuyama y defiendo su primacía en las Humanidades, con un verso de Javier Huapaya, poeta migrante a la capital:

Nada es más hermoso

Cuando meditamos un segundo

$\Upsilon$ abarcamos un siglo 